Supporting Information

\title{
Nanozymes-Engineered Metal-Organic Frameworks for Catalytic Cascades-Enhanced Synergistic Cancer Therapy
}

Chuang Liu, ${ }^{1,2}$ Jie Xing, ${ }^{1,2}$ Ozioma Udochukwu Akakuru,,${ }^{1,2}$ Lijia Luo, ${ }^{1}$ Shan Sun, ${ }^{1}$ Ruifen Zou, ${ }^{1,2}$ Zhangsen $\mathrm{Yu},{ }^{1}$ Qianlan Fang,,${ }^{1,2}$ and Aiguo $\mathrm{Wu}^{*}{ }^{1}$

${ }^{1}$ Cixi Institute of Biomedical Engineering, CAS Key Laboratory of Magnetic Materials and Devices, \& Key Laboratory of Additive Manufacturing Materials of Zhejiang Province, Ningbo Institute of Materials Technology and Engineering, Chinese Academy of Sciences, Ningbo 315201, P.R. China

${ }^{2}$ University of Chinese Academy of Sciences, Beijing, 100049, P.R. China

Corresponding author: Prof. Dr. Aiguo Wu (E-mail: aiguo@nimte.ac.cn; Tel: +86-574-86685039;

Fax: +86-574-86685039) 


\section{Experimental Section}

Materials: Polyvinyl pyrrolidone (PVP) $(\mathrm{Mw}=58,000)$ were purchased from SigmaAldrich (Shanghai, China). $\mathrm{FeCl}_{3} \cdot 6 \mathrm{H}_{2} \mathrm{O}(98 \%)$, and 2-aminoterephthalic acid $\left(\mathrm{NH}_{2}-\mathrm{BDC}, 99 \%\right)$ were purchased from Alfa Aesar (Shanghai, China). $\mathrm{HAuCl}_{4} \cdot 4 \mathrm{H}_{2} \mathrm{O}, \mathrm{Ti}\left(\mathrm{SO}_{4}\right)_{2}$ were purchased from Sinopharm Chemical Reagent Co. Ltd (Shanghai, China). 4,4',4',4','-(Porphine5,10,15,20-tetrayl) tetrakis(benzoic acid) $(97 \%), \mathrm{H}_{2} \mathrm{PtCl}_{6} \cdot 6 \mathrm{H}_{2} \mathrm{O}(37.5 \%), \mathrm{ZrOCl}_{2} \cdot 8 \mathrm{H}_{2} \mathrm{O}$, acetic acid (99.5\%), acetone, 9,10-Anthracenediyl-bis(methylene)dimalonic acid (ABDA, 90\%), hexane, 2',7'-Dichlorodihydrofluorescein diacetate (DCFH-DA, 97\%), $\mathrm{ZrCl}_{4}(99.9 \%)$, and N,NDimethylformamide (DMF, 99.5\%) were purchased from Aladdin Industrial Inc. (Shanghai, China). Deionized water (Millipore Milli-Q grade), with resistivity of $18.2 \mathrm{M} \Omega$, was used in all the experiments. All chemicals were used as received.

Synthesis of PCN and PVP-coated Pt NPs: PCN with a diameter of $50 \mathrm{~nm}$ was synthesized according to the reported procedure with slight changes. ${ }^{33}$ The chemical solutions were prepared as following: $150 \mathrm{mg} \mathrm{ZrOCl}_{2} \cdot 8 \mathrm{H}_{2} \mathrm{O}$ was dispersed in $15 \mathrm{~mL} \mathrm{DMF}$; $50 \mathrm{mg}$ $\mathrm{H}_{2}$ TCPP was dispersed in $20 \mathrm{~mL}$ DMF with sonication for $15 \mathrm{~min} ; 1.2 \mathrm{~g}$ benzoic acid was dispersed in $20 \mathrm{~mL}$ DMF. The above solutions were transferred into a one-neck round bottomed flask, sealed and stirred at $90{ }^{\circ} \mathrm{C}$ for $5 \mathrm{~h}$. The final PCN was obtained by centrifugation at 13,000 rpm for $25 \mathrm{~min}$, washed with DMF twice and dispersed in $10 \mathrm{~mL}$ DMF for further use. For the PVP-coated Pt NPs, $50.75 \mathrm{mg} \mathrm{H}_{2} \mathrm{PtCl}_{6} \cdot 6 \mathrm{H}_{2} \mathrm{O}$ was dissolved in $20 \mathrm{~mL}$ PVP-ethylene glycol solution $(222 \mathrm{mg}, \mathrm{Mw}=58,000)$ under sonication and then transferred into a $50 \mathrm{~mL}$ two-neck round bottomed flask, followed by reacting at $180{ }^{\circ} \mathrm{C}$ for $10 \mathrm{~min}$. After cooling to room temperature, the obtained dark-brown solution was added into $180 \mathrm{~mL}$ acetone and centrifuged at 9,000 rpm for $10 \mathrm{~min}$ to obtain colloidal dispersed PVP-coated Pt NPs. The precipitate was 
washed with acetone-hexane $(\mathrm{v} / \mathrm{v}=1: 1)$ twice to remove the excess free PVP and dispersed in 10 $\mathrm{mL}$ of DMF for further use.

Synthesis of P@Pt and P@Pt@P: 3 mL Pt NPs diluted with 6 mL DMF were added dropwise into $5 \mathrm{~mL}$ PCN under stirring for $6 \mathrm{~h}$ followed by centrifugation at 10,000 rpm for 10 min. The obtained P@Pt was then washed with DMF twice to remove unattached Pt NPs and dispersed in 5 mL DMF for further use. For the P@Pt@P, 2 mL P@Pt diluted with 3 mL DMF were placed in a one-neck round bottomed flask under stirring, followed by the addition of $1 \mathrm{~mL}$

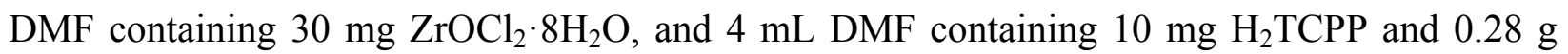
benzoic acid. Thereafter, the above solution was stirred for $30 \mathrm{~min}$ before heated to $90{ }^{\circ} \mathrm{C}$ for $5 \mathrm{~h}$. The P@Pt@P was collected by centrifugation at 12,000 rpm for 10 min, washed with DMF twice and dispersed in $10 \mathrm{~mL}$ DMF for further use.

Synthesis of P@Pt@P-Au and P@Pt@P-Au-FA: 2 mL P@Pt@P in DMF was dispersed in methanol overnight, followed by washing with pure water and dispersion in $20 \mathrm{~mL}$ pure water. The P@Pt@P-Au aqueous solution was placed in an ice-water bath under stirring, followed by the addition of $200 \mu \mathrm{L}$ of $50 \mathrm{mM} \mathrm{HAuCl}_{4}$ and stirring for $4 \mathrm{~min}$. Thereafter, $2 \mathrm{~mL}$ of freshly prepared ice-cold $\mathrm{NaBH} 4$ solution $\left(1 \mathrm{~mL}, 1.75 \mathrm{mg} \mathrm{mL}^{-1}\right)$ was added and stirred for $1 \mathrm{~min}$, followed by washing with DMF-water solution $(\mathrm{v} / \mathrm{v}=1: 1)$ twice and dispersion in DMF. For the P@Pt@P-Au-FA, 2 mg FA was added into 5 mL DMF solution containing 5 mg P@Pt@P-Au and stirred at $30^{\circ} \mathrm{C}$ for $12 \mathrm{~h}$, after which the excess free FA was removed by washing with DMF twice.

Synthesis of Pt@UiO-66- $\mathrm{NH}_{2}$ : 1.2 mL of acetic acid mixed with 2 mL Pt NPs was added into $10 \mathrm{~mL}$ DMF containing $10.2 \mathrm{mg} \mathrm{ZrCl}_{4}$ and $14.5 \mathrm{mg} \mathrm{NH} \mathrm{NH}_{2}$-BC. The mixture was then transferred into a $50 \mathrm{~mL}$ round bottomed flask for crystallization at $120{ }^{\circ} \mathrm{C}$ for $12 \mathrm{~h}$. The 
precipitate was collected by centrifugation at $9,000 \mathrm{rpm}$ for $5 \mathrm{~min}$, washed with alcohol and water, and dispersed in water for further use.

The stability of P@Pt@P and P@Pt@P-FA in PBS: 5 mM PBS solution containing 100 $\mu \mathrm{m} \mathrm{mL}^{-1}$ of $\mathrm{P} @ \mathrm{Pt} @ \mathrm{P}$ or $\mathrm{P} @ \mathrm{Pt} @ \mathrm{P}-\mathrm{FA}$ was kept at $37^{\circ} \mathrm{C}$ for various hours and directly dropped on a carbon film deposited copper mesh for TEM analysis.

In Vitro $\mathrm{H}_{2} \mathrm{O}_{2}$ Catalytic Test: The concentration of $\mathrm{H}_{2} \mathrm{O}_{2}$ was determined by UV-vis absorbance at $405 \mathrm{~nm}$ based on the specific reaction between $\mathrm{H}_{2} \mathrm{O}_{2}$ and $\mathrm{Ti}\left(\mathrm{SO}_{4}\right)_{2}$ solutions, the color of which would change from colorless to yellow. $100 \mu \mathrm{g} \mathrm{mL} \mathrm{L}^{-1}$ of PCN or P@Pt@P or $\mathrm{P} @ \mathrm{Pt} @ \mathrm{P}-\mathrm{Au}$ containing $30 \mathrm{mM} \mathrm{H} \mathrm{H}_{2} \mathrm{O}_{2}$ was kept at $37{ }^{\circ} \mathrm{C}$ for various minutes followed by centrifugation. Then $0.35 \mathrm{~mL}$ of each supernatant was mixed with $2.65 \mathrm{~mL} \mathrm{Ti}\left(\mathrm{SO}_{4}\right)_{2}$ solution (500 mg Ti( $\left(\mathrm{SO}_{4}\right)_{2}$ was dissolved in $50 \mathrm{~mL}$ water containing $8.33 \mathrm{~mL}$ of $\mathrm{H}_{2} \mathrm{SO}_{4}$ ) and the UV-vis absorbance was measured.

Singlet Oxygen Generation: Water-soluble ABDA was used as the ROS indicator, the UV-vis absorbance at $380 \mathrm{~nm}$ of which would be decreased in the presence of ${ }^{1} \mathrm{O}_{2}$. In a typical experiment, 1 mL of $100 \mu \mathrm{g} \mathrm{mL}^{-1} \mathrm{PCN}$ or P@Pt@P or P@Pt@P-Au solution containing 0.14 $\mathrm{mM}$ ABDA was irradiated under $671 \mathrm{~nm}$ laser for $0,4,8,12,16$, and 20 min respectively, and the UV-vis absorbance changes were measured. As a control, $1 \mathrm{~mL}$ of $0.14 \mathrm{mM}$ ABDA was consistent with the above step. As for the hypoxia-mimicking conditions, PCN or P@Pt@P solution containing $0.14 \mathrm{mM}$ ABDA was evacuated for $30 \mathrm{~min}$, followed by flushing with nitrogen for $1 \mathrm{~h}$ to remove the dissolved oxygen. Thereafter, $\mathrm{H}_{2} \mathrm{O}_{2}$ was added into the solution and irradiated by laser.

Detection of Gluconic Acid: Gluconic acid, as a product of glucose oxidation reaction, was analyzed according to a reported method. First, $100 \mu \mathrm{g} \mathrm{mL} \mathrm{m}^{-1} \mathrm{P} @ \mathrm{Pt} @ \mathrm{P}-\mathrm{Au}$ solution containing 
$4.5 \mathrm{mg} \mathrm{mL}-1$ of $\beta$-D-glucose was kept at $37^{\circ} \mathrm{C}$ for 1,3 , and $5 \mathrm{~h}$, respectively, and $0.8 \mathrm{~mL}$ of the supernatant was obtained by centrifugation. Next, the supernatant was mixed with $250 \mu \mathrm{L}$ aqueous solution of $5 \mathrm{mM}$ EDTA and $0.15 \mathrm{mM}$ trimethylamine, followed by mixing with $25 \mu \mathrm{L}$ of $3 \mathrm{M}$ hydroxylamine. The above solution was incubated for $25 \mathrm{~min}$, followed by addition of $125 \mu \mathrm{L}$ aqueous solution containing $1 \mathrm{M} \mathrm{HCl}, 0.1 \mathrm{M} \mathrm{FeCl}_{3}$ and $0.25 \mathrm{M} \mathrm{CCl}_{3} \mathrm{COOH}$, and the absorbance was recorded by the UV-vis spectrophotometer (PerkinElmer LAMBDA 950).

Cell Culture and Cell Viability Test: 4T1 murine breast cancer cells were cultured by Roswell Park Memorial Institute (RPMI) 1640 Medium containing 10\% fetal bovine serum (FBS) and $1 \%$ antibiotics $\left(10,000 \mathrm{U} \mathrm{mL}^{-1}\right.$ penicillin-streptomycin) under $37{ }^{\circ} \mathrm{C}$ with $5 \% \mathrm{CO}_{2}$. The $4 \mathrm{~T} 1$ cells pre-seeded in 96-well plates were incubated with $100 \mu \mathrm{L}$ RPMI-1640 containing various concentrations of PCN-FA, P@Pt@P-FA, and P@Pt@P-Au-FA for 24 h. Thereafter, cells were washed with PBS and re-cultured with $100 \mu \mathrm{L}$ of fresh medium, followed by addition of $10 \mu \mathrm{L}$ of MTT ( $\left.5 \mathrm{mg} \mathrm{mL}^{-1}\right)$ and further incubated for another $4 \mathrm{~h}$. After that, the culture medium was removed before the addition of $100 \mu \mathrm{L}$ DMSO. The optical density at $490 \mathrm{~nm}$ was measured using a microplate reader (Bio-rad imark).

Intracellular $\mathrm{H}_{2} \mathrm{O}_{2}$ Catalytic Test: Intracellular $\mathrm{H}_{2} \mathrm{O}_{2}$ was detected by ROS fluorescence probe of DCFH-DA. The 4T1 cells pre-seeded in 24-well plates were incubated with $100 \mu \mathrm{g} \mathrm{mL}$ 1 of P@Pt@P-Au-FA or PCN-FA for 12 h. Then, the cells were washed with PBS and recultured with $1 \mathrm{~mL}$ of fresh medium containing $100 \mu \mathrm{M} \mathrm{H}_{2} \mathrm{O}_{2}$ for 30 min. Thereafter, the above medium was removed, washed with PBS, and stained with $100 \mathrm{mM}$ DCFH-DA for $15 \mathrm{~min}$. The fluorescence was observed on a fluorescent microscope (Leica DMI3000).

In vitro PDT and Live-dead Cell Staining: 4T1 cells pre-seeded in 96-well plates were incubated with $100 \mu \mathrm{g}$ mL-1 of PCN-FA, P@Pt@P-FA, or P@Pt@P-Au-FA for 12 h. The cells 
were thereafter cleaned with PBS and re-cultured with $100 \mu \mathrm{L}$ of fresh medium. Then, the cells were exposed to laser irradiation for various minutes before incubating for another $24 \mathrm{~h}$, and the cell viabilities were measured following the MTT assay. The construction of hypoxia-mimicking condition was carried out according to a reported method. Briefly, 96-well plates were placed inside of a transparent box, evacuated for $30 \mathrm{~min}$ and flushed into nitrogen for 1 hour. Then, the 96-well plates were sealed with parafilm and irradiated with laser.

Tumor Model and In Vivo Imaging: Female BALB/c mice were purchased from Nanjing Cavins Biotechnology Co., Ltd (Nanjing, China) and used under protocols approved by the Regional Ethics Committee for Animal Experiments at Ningbo University, China (Permit No. SYXK (Zhe) 2019-0005). The 4T1 cells $\left(1 \times 10^{6}, 100 \mu \mathrm{L}\right)$ suspended in RPMI-1640 were injected into the back (right flank region) of the female BALB/c mice (14-15 g, aged 4-5 weeks) and the animal experiments were performed when the tumor reached about $150 \mathrm{~mm}^{3}$ (tumor volume $=$ width $\times$ width $\times$ L/2). For the in vivo imaging, the P@Pt@P-Au-FA $(100 \mu \mathrm{L}, 2$ mg $\mathrm{mL}^{-1}$ ) after i.v. injection into the $4 \mathrm{~T} 1$ tumor-bearing mice were tracked by a small animal imaging system (IVIS ${ }^{\circledR}$ Lumina III PerkinElmer; parameters: Ex, 640 nm; Em, 710 nm).

Evaluation of Intratumoral Oxygenation: The $\mathrm{O}_{2}$-evolving ability of the P@Pt@P-AuFA towards intratumoral $\mathrm{H}_{2} \mathrm{O}_{2}$ was monitored using $\mathrm{Vevo}^{\circledR}$ LAZR-X. The entire tumor oxygenation saturation levels before and after i.v. injection of the P@Pt@P-Au-FA (100 $\mu \mathrm{L}, 2$ $\mathrm{mg} \mathrm{mL} \mathrm{m}^{-1}$ ) was imaged under the Oxy-hemo mode according to the standard protocol by the manufacturer. The optical absorption of oxygenated and deoxygenated hemoglobin was measured at different wavelengths of 850 and $750 \mathrm{~nm}$, respectively.

In Vivo Cascades Reaction-based Antitumor Therapy: For in vivo therapy, 4T1 tumorbearing mice whose initial tumor volumes approached $150 \mathrm{~mm}^{3}$ were randomly divided into the 
following six groups $(n=6)$ : PBS injection with $671 \mathrm{~nm}$ laser irradiation $(\mathrm{PBS}+\mathrm{L})$ as the control group, P@Pt@P-FA injection alone (P@Pt@P-FA), P@Pt@P-Au-FA injection alone (P@Pt@P-Au-FA), PCN-FA injection with 671 nm laser irradiation (PCN-FA + L), P@Pt@PFA injection with 671 nm laser irradiation (P@Pt@P-FA + L), as well as P@Pt@P-FA injection with 671 nm laser irradiation (P@Pt@P-Au-FA + L). At 22 h post i.v. injection of $100 \mu \mathrm{L} 2 \mathrm{mg}$ $\mathrm{mL}^{-1}$ of each samples into $4 \mathrm{~T} 1$ tumor-bearing mice, the mice were exposed to a $671 \mathrm{~nm}$ laser with a powder density of $300 \mathrm{~mW} \mathrm{~cm}^{-2}$ for $8 \mathrm{~min}$. The exposure day of the mice to laser treatment was recorded as day 0 . The tumor volumes and body weights were recorded every two days from the beginning of the treatment. 

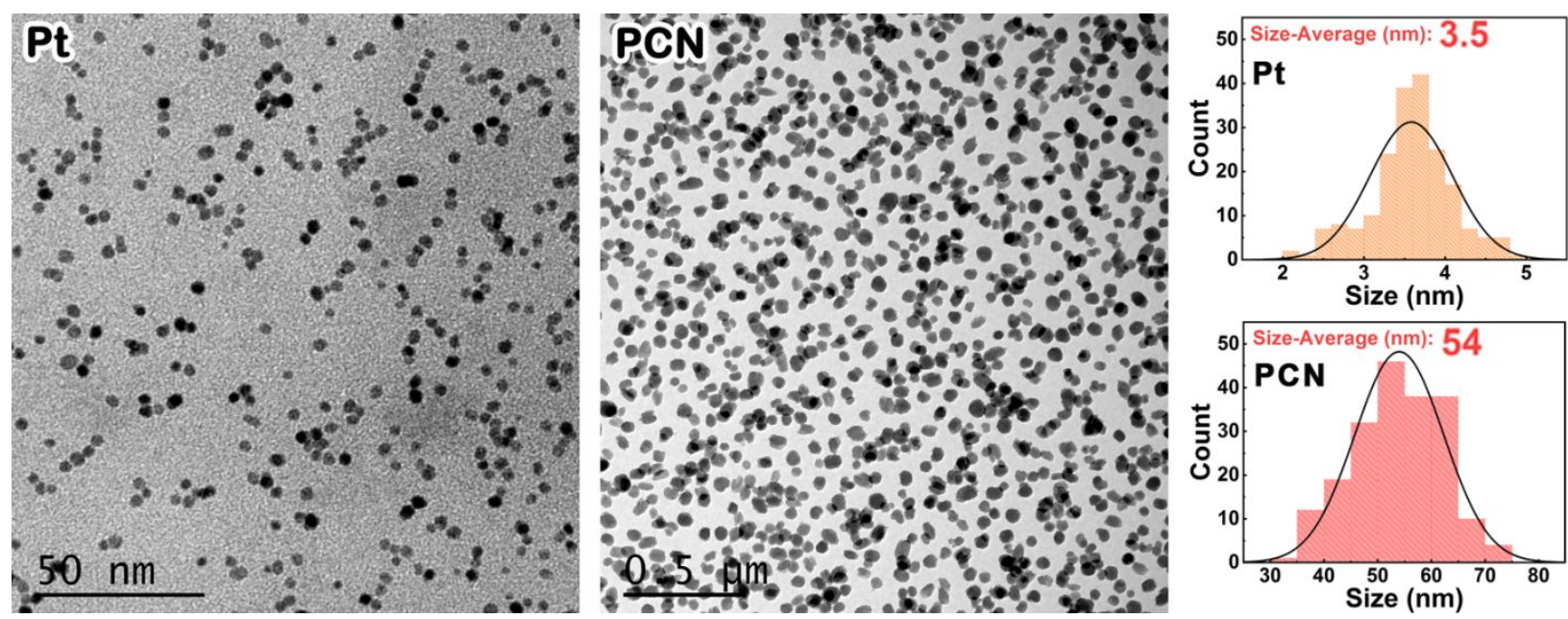

Figure S1. TEM images of highly uniformed Pt NPs (3.5 nm) and PCN NPs (54 nm).

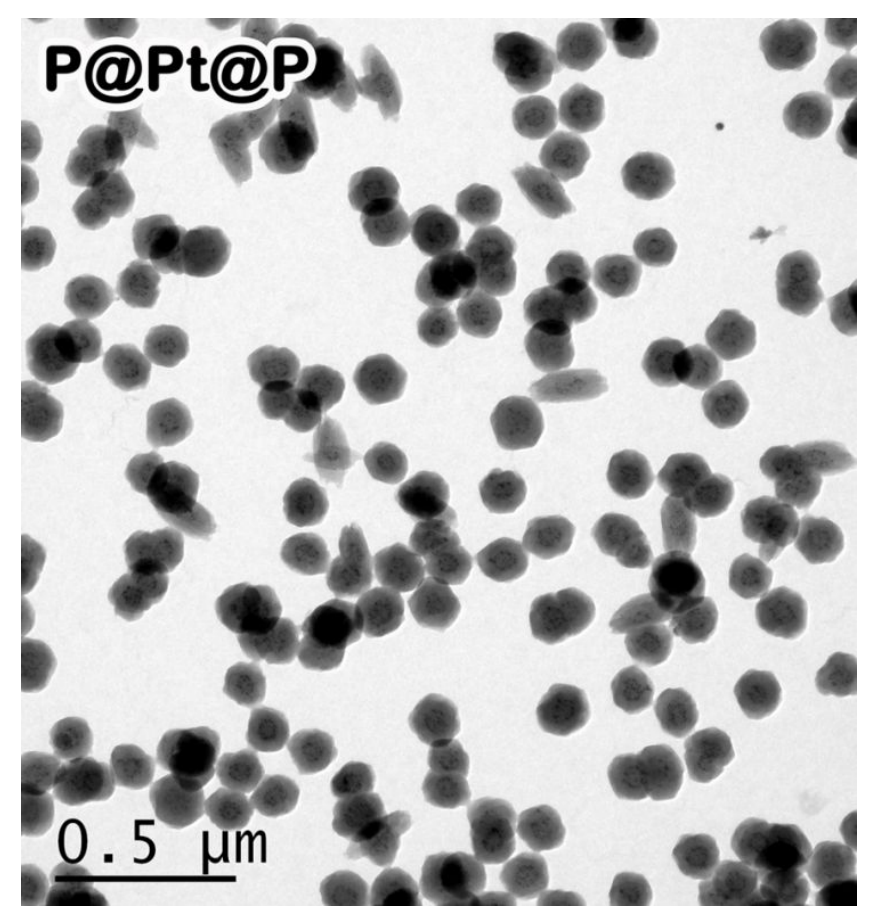

Figure S2. TEM image of the as-synthesized P@Pt@P with a sandwich structure in nearly 100\% yeilds. 


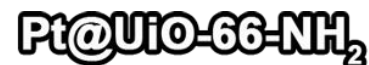

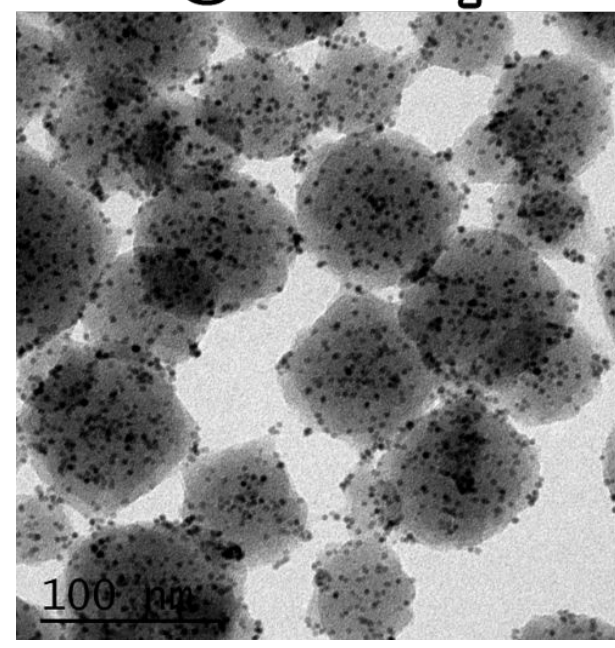

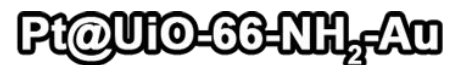

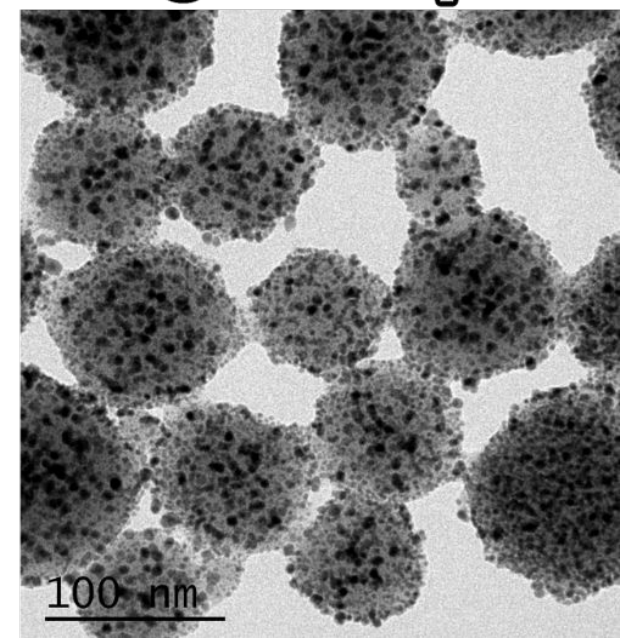

Figure S3. TEM images of the core-shell structured Pt@UiO-66- $\mathrm{NH}_{2}$ and the fabricated $\mathrm{Pt} @$ UiO-66- $\mathrm{NH}_{2}-\mathrm{Au}$ via sodium borohydride reduction. In a typical procedure to confine and stabilize the growth of the $\mathrm{Au} \mathrm{NPs}, \mathrm{HAuCl}_{4}$ was introduced into the aqueous solution of $\mathrm{P} @$ UiO-66- $\mathrm{NH}_{2}$ in an ice-water bath under stirring, followed by the addition of $\mathrm{NaBH}_{4}$ to reduce $\mathrm{Au}$ (III) to $\mathrm{Au}(0)$ (P@Pt@P-Au). However, after adjusting the diverse experimental parameters, the Pt NPs uncontrollably served as the nucleation cores for the growth of gold, leading to significantly reduced catalase-mimicking ability of Pt NPs. Therefore, it is a smart and necessary strategy in our work to apply sandwich structure for achieving dual-nanozymes-engineered MOFs-based nanoreactor.

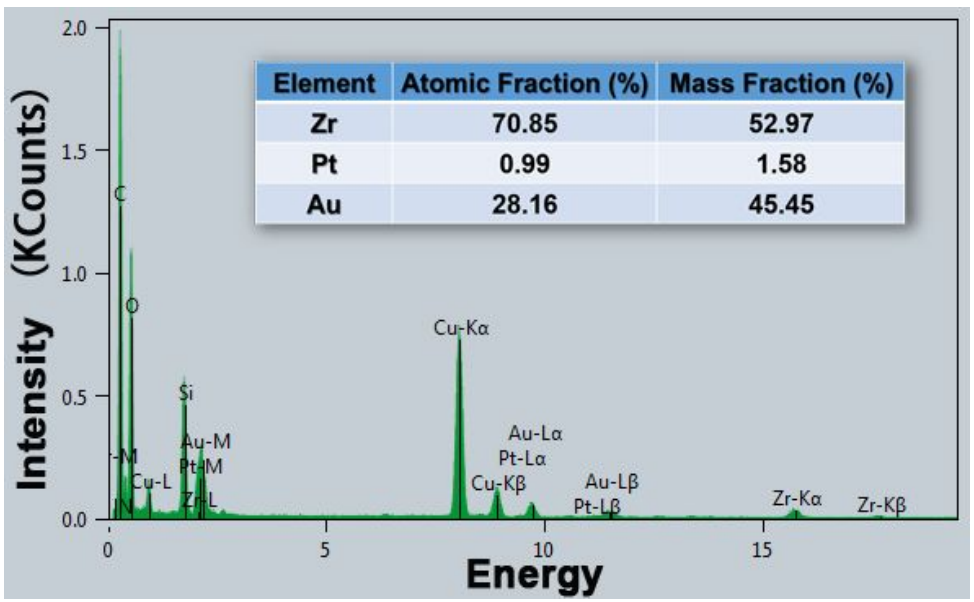

Figure S4. The EDS spectrum of P@Pt@P-Au. 


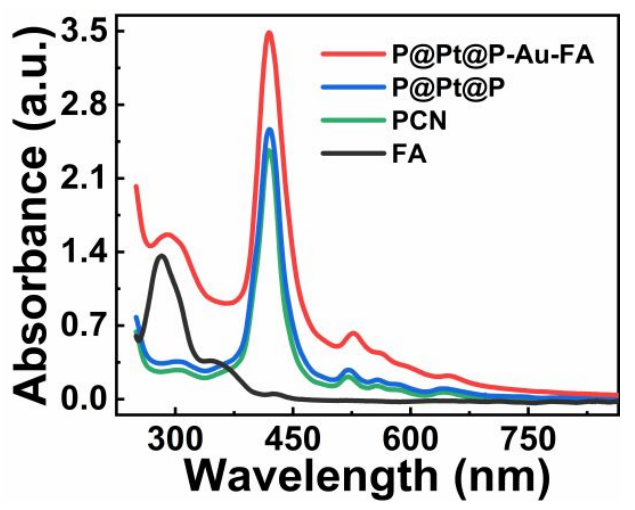

Figure S5. The UV-vis-NIR absorbance spectra of FA, PCN (50 nm), P@Pt@P, and P@Pt@PAu-FA during each synthesis step, indicating the successful modification of FA on P@Pt@P-Au.

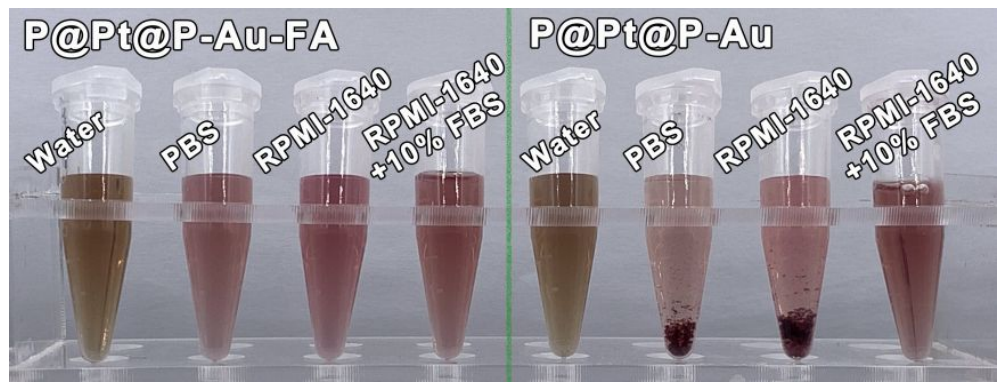

Figure S6. The stability study of PCN@Pt@PCN-Au before and after modification of FA was investigated in our revised manuscript by distributing them into different physiological solutions for $24 \mathrm{~h}\left(\mathrm{H}_{2} \mathrm{O}, \mathrm{PBS}\right.$, cell culture medium, and cell culture medium plus $10 \%$ fetal bovine serum).
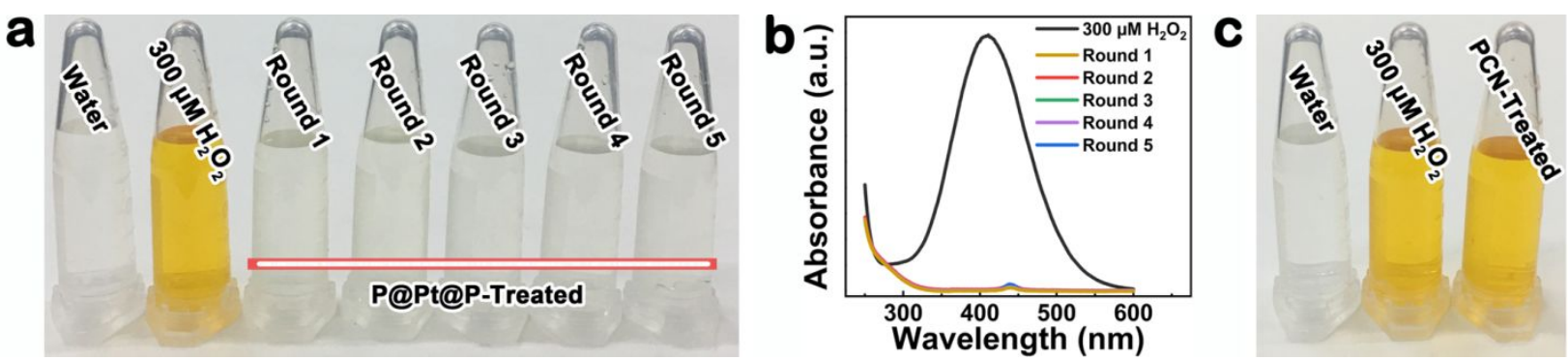

Figure S7. a) The catalsae-mimicking performance of P@Pt@P $\left(100 \mu g\right.$ mL $\left.\mathrm{L}^{-1}\right)$ examined by the repetitive addition of $\mathrm{H}_{2} \mathrm{O}_{2}$ every 10 min (the yellow color corresponds to the existence of $\mathrm{H}_{2} \mathrm{O}_{2}$ ), and $b)$ the corrsponding UV-vis-NIR absorbance spectra for each time. c) PCN (100 $\left.\mu \mathrm{g} \mathrm{mL}^{-1}\right)$ showed no response to $\mathrm{H}_{2} \mathrm{O}_{2}$. 

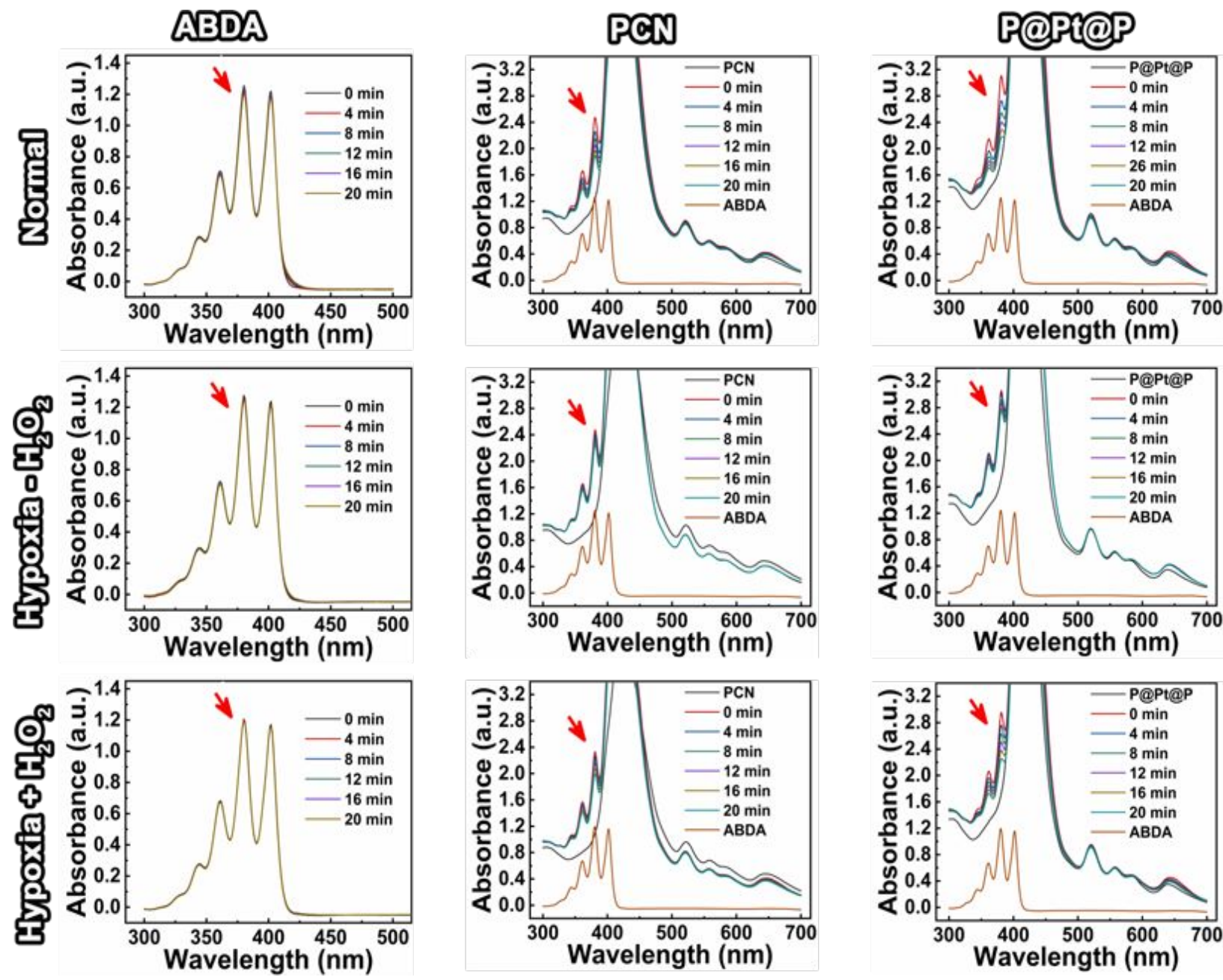

Figure S8. The UV-vis-NIR absorbance change of ABDA $(0.14 \mathrm{mM})$ alone, PCN $\left(100 \mu \mathrm{g} \mathrm{mL}^{-1}\right)$ containing $0.14 \mathrm{mM}$ ABDA, and P@Pt@P $\left(100 \mu \mathrm{g} \mathrm{mL}^{-1}\right)$ containing $0.14 \mathrm{mM}$ ABDA under normal condition and hypoxia-mimicking condition with or without the addition of $\mathrm{H}_{2} \mathrm{O}_{2}$ after various minutes of $671 \mathrm{~nm}$ laser irradiation $\left(300 \mathrm{~mW} \mathrm{~cm}^{-2}\right)$, respectively.

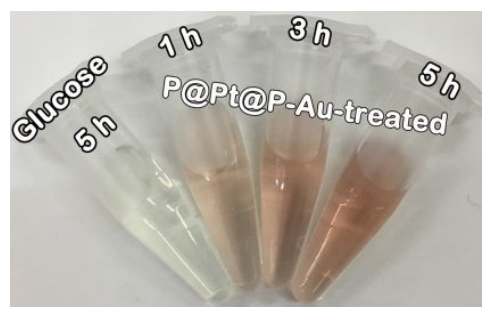

Figure S9. P@Pt@P-Au $\left(100 \mu \mathrm{g} \mathrm{mL} \mathrm{L}^{-1}\right)$ was incubated with $4.5 \mathrm{mg} \mathrm{mL} \mathrm{m}^{-1}$ of $\beta$-D-glucose under $37^{\circ} \mathrm{C}$ for $1 \mathrm{~h}, 3 \mathrm{~h}$, and $5 \mathrm{~h}$ respectively, followed by centrifugation. The supernatant of which was analyzed by colorimetric assay, and the pink color corresponds to the production of gluconic acid. 

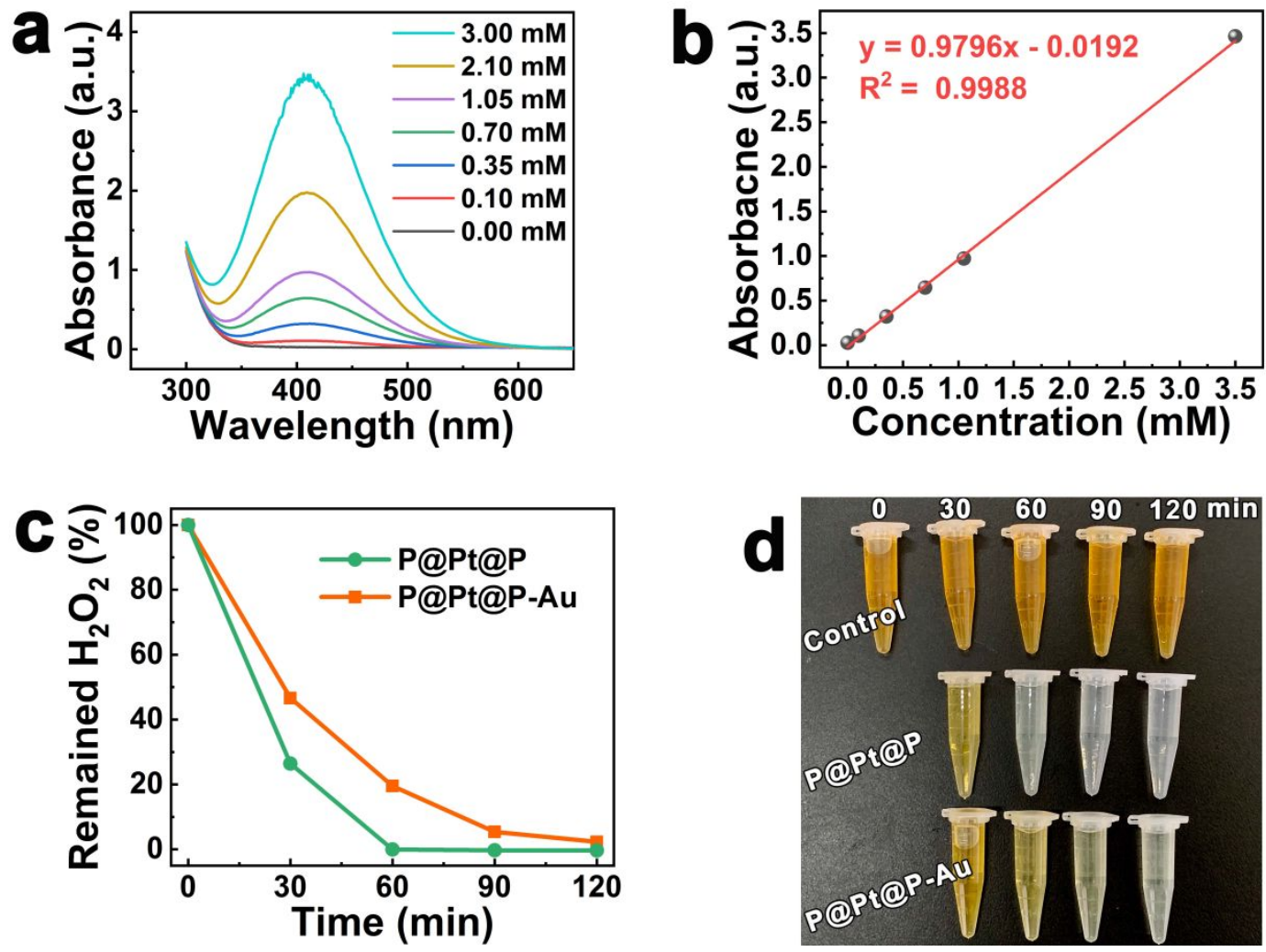

Figure S10. a) The UV-vis-NIR absorption spectra and b) the stranded curve of $\mathrm{H}_{2} \mathrm{O}_{2}$ with different concentrations. c) The catalsae-mimicking performance of P@Pt@P and P@Pt@P-Au (100 $\mu \mathrm{g} \mathrm{mL}^{-1}$ ) incubated with $30 \mathrm{mM} \mathrm{H}_{2} \mathrm{O}_{2}$ at $37{ }^{\circ} \mathrm{C}$ for various minutes and d) the coresponding color change (the yellow color corresponds to the existence of $\mathrm{H}_{2} \mathrm{O}_{2}$ ).
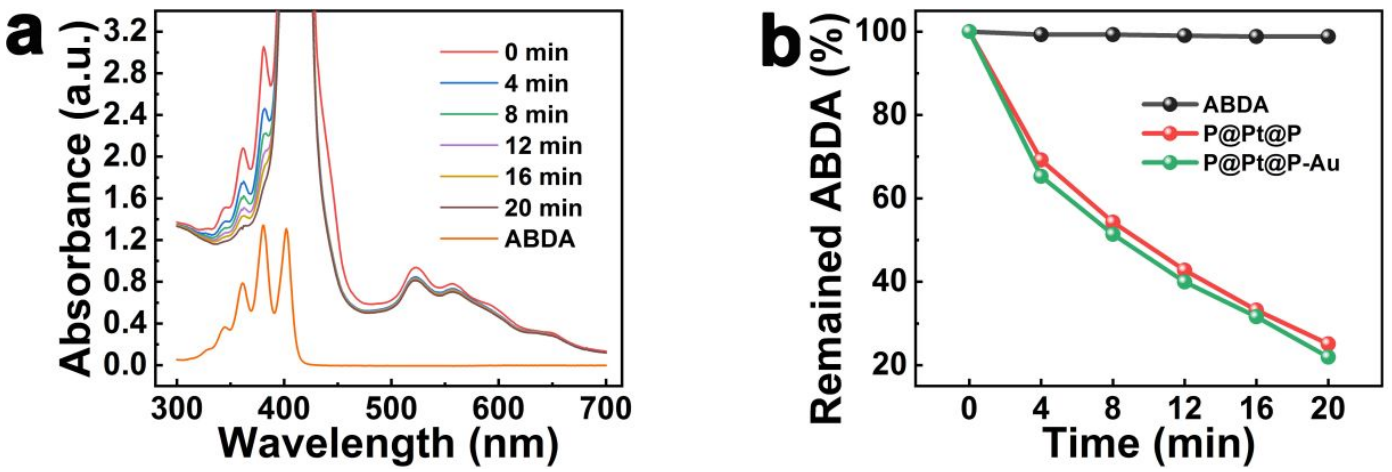

Figure S11. a) The UV-vis-NIR absorbance change of ABDA (0.14 mM) alone, P@Pt@P (100 $\left.\mu \mathrm{g} \mathrm{mL}^{-1}\right)$ containing $0.14 \mathrm{mM}$ ABDA, and P@Pt@P-Au $\left(100 \mu \mathrm{g} \mathrm{mL}^{-1}\right)$ containing $0.14 \mathrm{mM}$ ABDA after various minutes of $671 \mathrm{~nm}$ laser irradiation $\left(300 \mathrm{~mW} \mathrm{~cm}^{-2}\right)$. b) The PDT efficacy of P@Pt@P or P@Pt@P-Au evaluated by calculating the remained percentage of ABDA. 


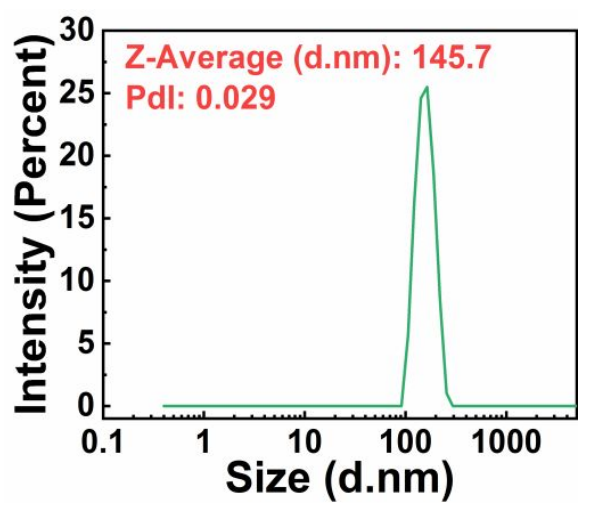

Figure S12. The hydrodynamic size of P@Pt@P-FA.
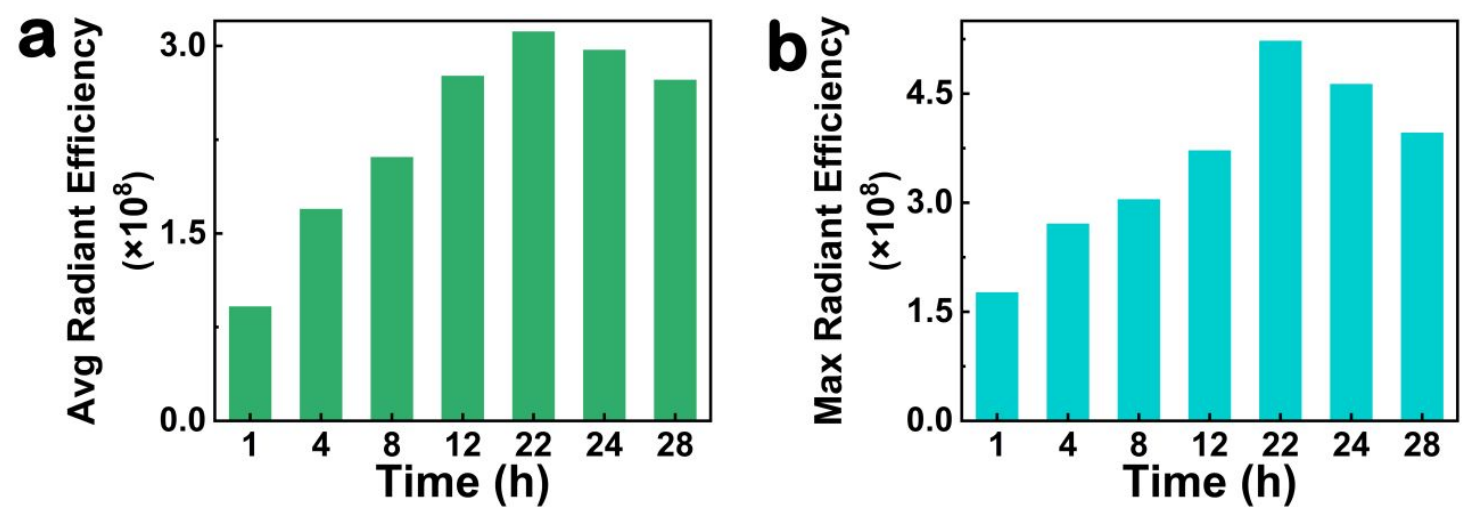

Figure S13. The quantitative analysis of a) the average and b) the maximum radiant efficiencies of P@Pt@P-Au-FA-injected $\left(100 \mu \mathrm{L}, 2\right.$ mg mL $\left.{ }^{-1}\right)$ mice calculated from the time-depended in vivo fluorescence images of tumors.

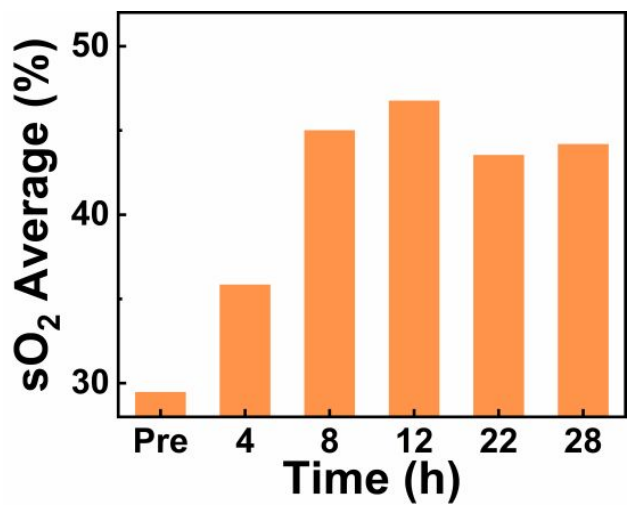

Figure S14. The quantitative analysis of the average oxygen saturation level $\left(\mathrm{sO}_{2}\right.$ average $)$ within the entire tumor after i.v. injection of P@Pt@P-Au-FA $\left(100 \mu \mathrm{L}, 2 \mathrm{mg} \mathrm{mL}^{-1}\right)$ for various hours. 


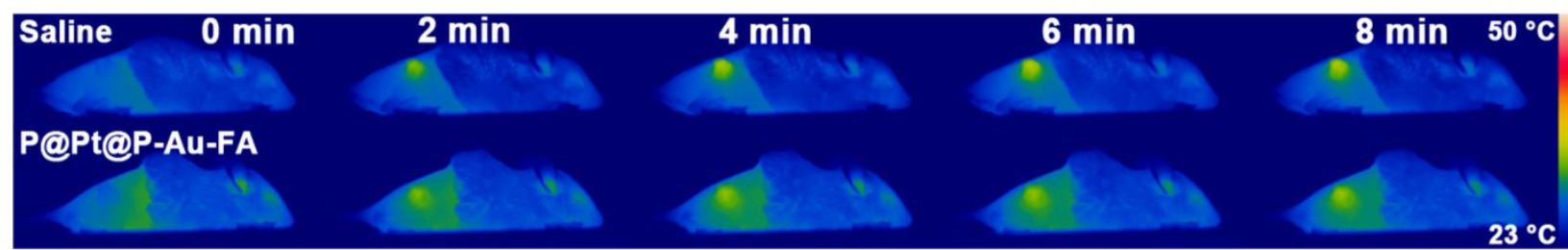

Figure S15. The infrared thermal images of $4 \mathrm{~T} 1$ tumor-bearing mice at $22 \mathrm{~h}$ post i.v. injection of PBS or P@Pt@P-Au-FA (100 $\mu \mathrm{L}, 2$ mg mL-1) upon $671 \mathrm{~nm}$ laser irradiation $(300 \mathrm{~mW} \mathrm{~cm}-2)$ for various minutes.

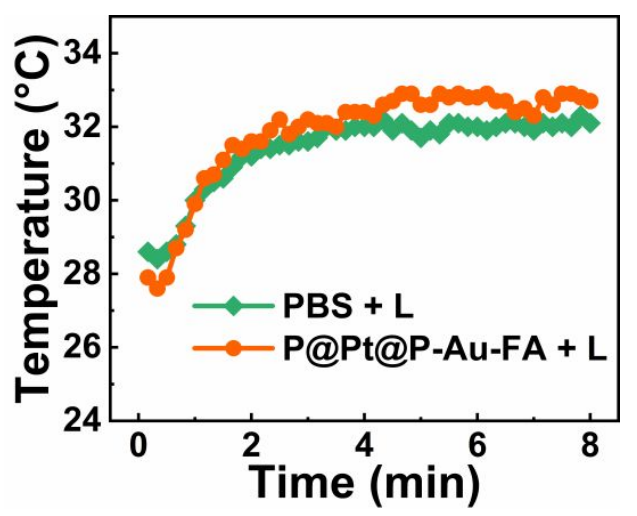

Figure S16. The recorded temperature changes of the tumor on mice at $22 \mathrm{~h}$ post i.v. injection of PBS or P@Pt@P-Au-FA (100 $\mu \mathrm{L}, 2$ mg mL $\left.{ }^{-1}\right)$ upon $671 \mathrm{~nm}$ laser exposure $\left(300 \mathrm{~mW} \mathrm{~cm}{ }^{-2}\right)$.
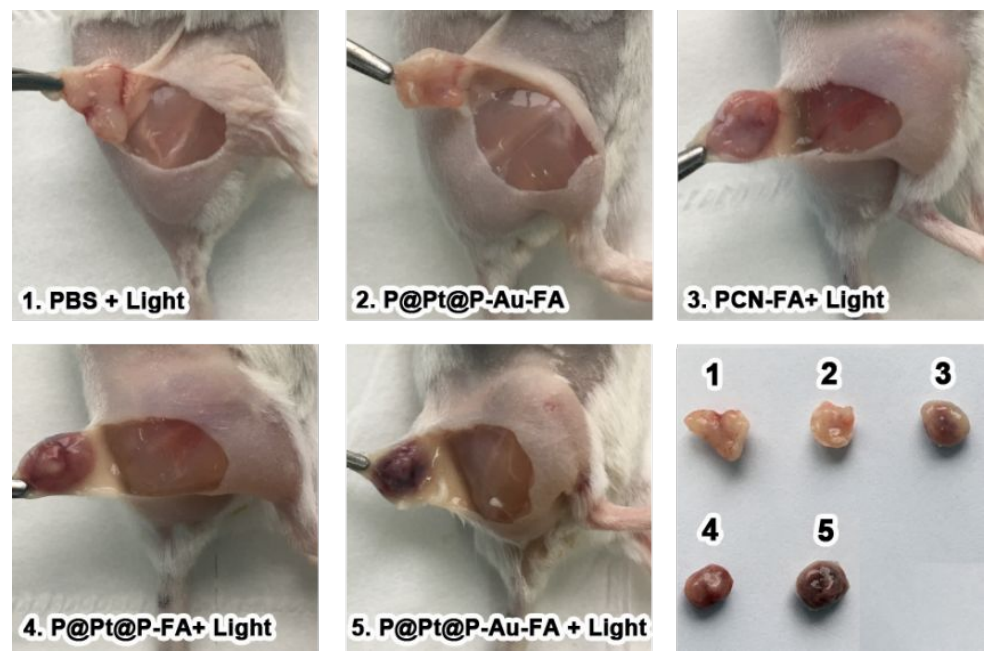

Figure S17. Five groups of mice at $22 \mathrm{~h}$ post i.v. injection of various samples received different treatments $\left(300 \mathrm{~mW} \mathrm{~cm}{ }^{-2}\right.$ for laser irradiation of $\left.8 \mathrm{~min}\right) .24 \mathrm{~h}$ later, the tumors were dissected and photographed. 


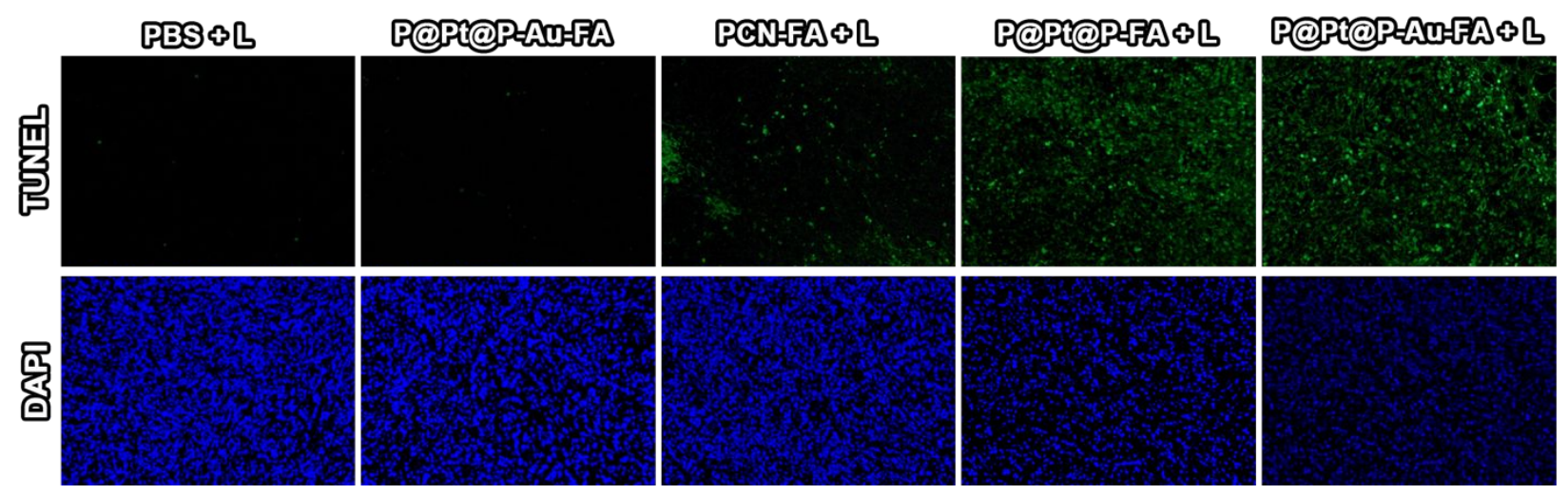

Figure S18. TUNEL and DAPI staining of the dissected tumors which underwent different treatments.

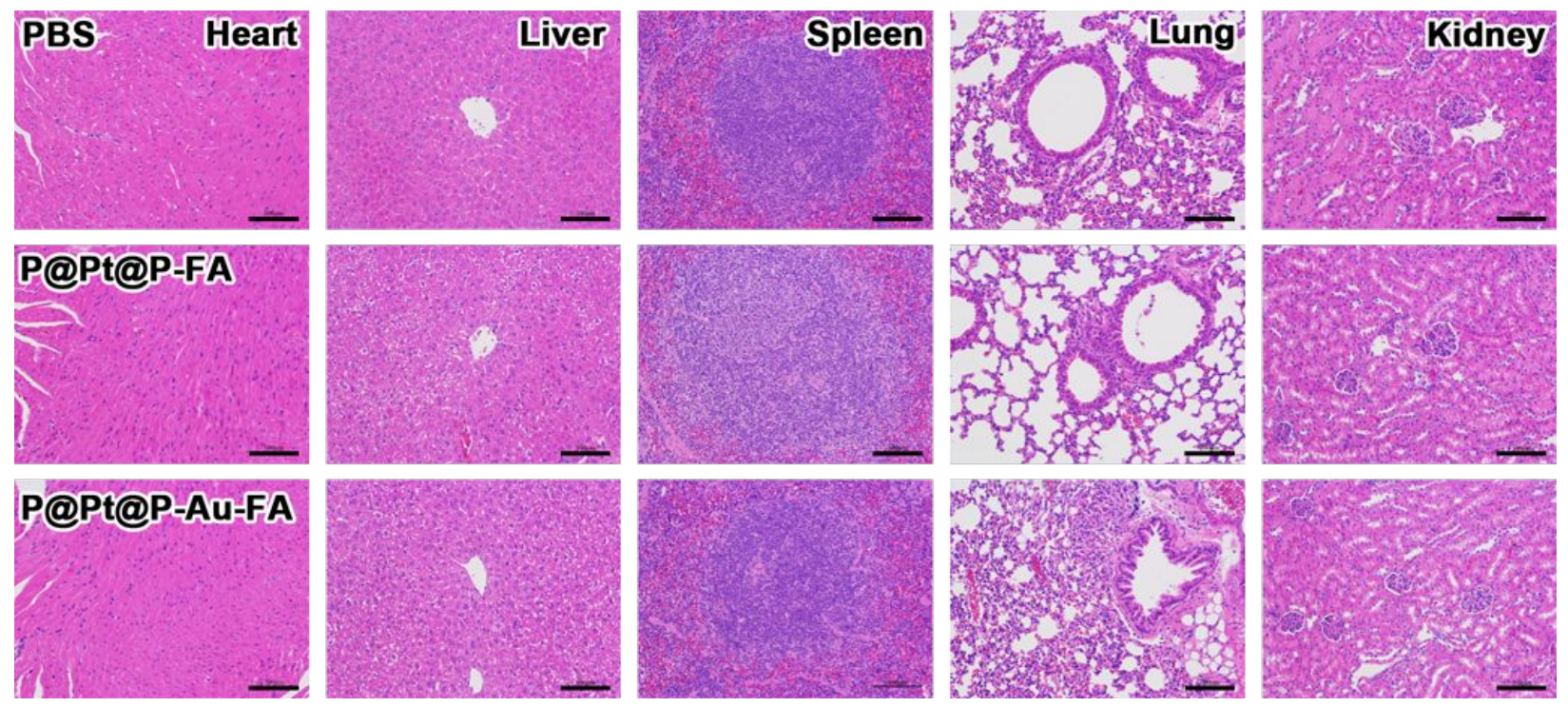

Figure S19. H\&E-stained slides of the main organs (heart, liver, spleen, lung, and kidney) collected from healthy mice after i.v. injection with different samples $\left(100 \mu \mathrm{L}, 2 \mathrm{mg} \mathrm{mL}^{-1}\right)$ for two weeks. 


\begin{tabular}{|c|c|c|}
\hline & PBS & P@Pt@P-Au-FA \\
\hline TP $(\mathrm{g} / \mathrm{L})$ & 51.8 & 55.2 \\
\hline ALB $(\mathrm{g} / \mathrm{L})$ & 26.5 & 27.5 \\
\hline $\mathrm{GLO}(\mathrm{g} / \mathrm{L})$ & 25.3 & 27.7 \\
\hline $\mathrm{A} / \mathrm{G}$ & 1.05 & 0.99 \\
\hline $\mathrm{ALT}(\mathrm{U} / \mathrm{L})$ & 39 & 41 \\
\hline AST $(\mathrm{U} / \mathrm{L})$ & 123 & 135 \\
\hline ALP $(\mathrm{U} / \mathrm{L})$ & 163 & 174 \\
\hline UERA $(\mathrm{mmol} / \mathrm{L})$ & 9.78 & 9.91 \\
\hline
\end{tabular}

Figure S20. Blood biomedical level of mice with i.v. injection of P@Pt@P-Au-FA (100 $\mu \mathrm{L}, 2$ $\mathrm{mg} \mathrm{mL^{-1 }}$ ) for two weeks.

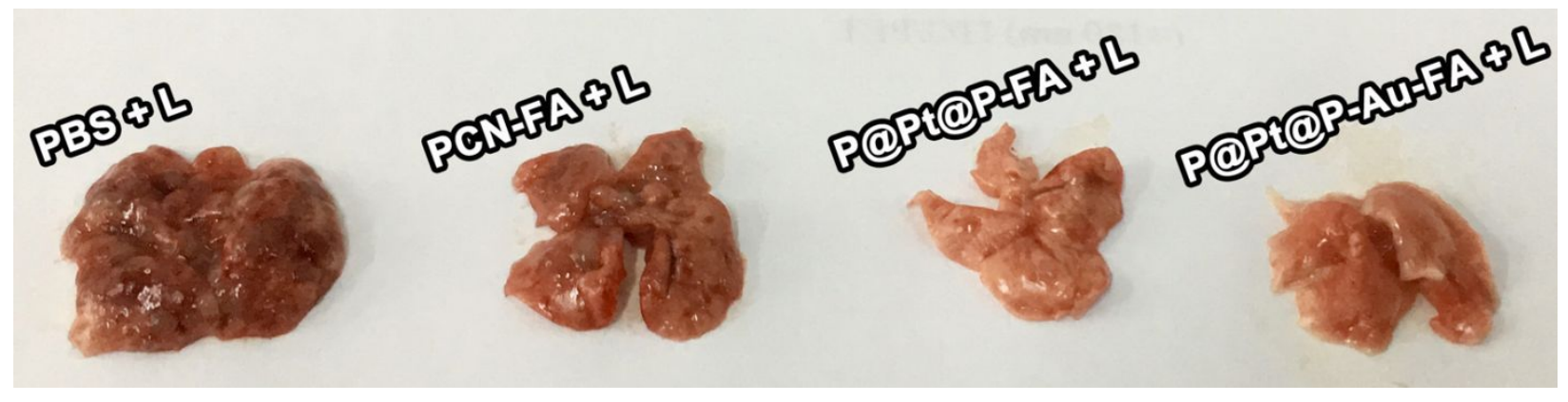

Figure S21. The representative lungs dissected from mice in the control group and the PDTtreated groups on day 14 . 